\section{The injured brain}

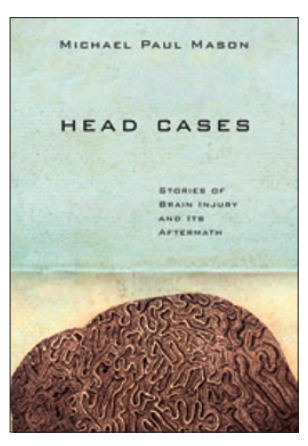

\section{Head Cases}

\section{By Michael Paul Mason}

Farrar, Straus \& Giroux, 2008

310 pp, hardcover, \$25

ISBN: 0374134529

\section{Reviewed by Masud Husain}

Translation of basic findings for the benefit of people with neurological conditions is currently one of the biggest drivers of neuroscience research. The trouble is that many neuroscientists don't know what it's like to have suffered brain injury or to care for someone who has. Despite the discomfort, confronting the results of brain injury in people can be an arresting, and moving, experience, one which sometimes has the power to motivate research in unexpected ways.

In Head Cases, Michael Mason attempts to give a voice to the many individuals who are left to deal with the consequences of brain injury. Most of his accounts are about people with traumatic brain injury (TBI). However, in these pages you'll also find individuals who have suffered viral encephalitis, hypoxic brain injury or the disruptive behavioral effects of a neuroepithelial tumor. But it's TBI that gets the greatest attention here, from accidents on highways to those occurring in civilians and servicemen in Iraq. Although it leads to more than a million Americans being treated every year, the real problem with TBI is its aftermath. In the US alone, a staggering five million people live with long-term effects that have a substantial impact on their daily lives. The figures worldwide are unknown, but are probably vast.

There are several intertwining themes in this book. First and foremost, there is a genuine attempt to convey to the general reader, through personal stories, some of the catastrophic consequences of brain injury. Many of the chapters contain accounts of patients and relatives that Mason has met. There are stories here of people whose lives have been shattered by recurrent seizures, memory loss, inappropriate or violent behavior, or simply difficulties with cognitive abilities that we take for granted every day.

In Head Cases we are introduced to the consequences of so-called 'frontal executive' deficits. For example, there's the high-flying PR director who excelled at organizing people, making effective decisions and multi-tasking. After her automobile accident, however, all of these abilities crumbled, leaving her overwhelmed and withdrawn. Then there's the snowboarder who, after sustaining his head injury, can't stop himself from telling diners at the restaurant where he works to shove it. There is even the gifted artist, injured in childhood, whose closest friend says that she's the most difficult person he knows: sometimes moody, sometimes impulsive and disinhibited, and sometimes just brilliant.

These stories are really engaging and would be enlightening to any neuroscientist who wants to find out more about the human outcomes of brain injury. However, I suspect that, like me, they would also become a little frustrated with several other themes that meander through these pages. Mason is clearly a well-read man who has developed a deep interest in literature from Western and other cultures. But the recurrent insertion of asides on subjects as diverse as Dante, Zen Buddhism and Cherokee rituals really don't work. If the motivation was to improve our understanding of brain injury, I'm afraid that these detours lack explanatory power. If the idea was to craft stories that one might read in a literary magazine such as Granta, it also fails because most of the time they're just plain awkward.

Another subject that pervades the book is the relationship between the self and the brain. Mason doesn't really have any answers here, but he keeps asking who we become once our fragile brains are injured. There is no room here for a scientific perspective because apparently science "cannot tell you who you are" either. We are left confused and can muse only whether a quote from Shakespeare or some Tibetan monk really compensates for the lack of any deep perspective from the author himself.

Mason is on firmer ground with his clear understanding of just how difficult it is to get proper and dedicated rehabilitation for most victims of brain injury. He works as a brain injury case manager for a rehabilitation facility in the United States and is able to describe why and how most patients don't get access to specialized services. This is a failure at a national level, echoed throughout the globe, in funding clinical facilities, research and education. Unfortunately, rather than focusing on policymakers, Mason's anger seems to be directed at neurologists and neurosurgeons. The impression that you might get from these pages is that many such clinicians have no idea what they're doing, despite apparently saving some of the lives he describes. Perhaps this also explains some of the technical errors, such as the assertion that fixed, dilated pupils in TBI results from the optic nerve being "pinched." Clearly, a neurologist didn't proofread the copy!

Head Cases will be a frustrating read for most neuroscientists. There is little in the way of useful neurobiology here, but the book does have several virtues, offering a passionate series of vignettes that sympathetically illuminates what happens to people after brain injury. However, it is too ambitious and superficial in taking on philosophical issues that are far beyond its scope, and perhaps these would have been better left out. In this case, less might have amounted to a great deal more. 